\title{
Prevalence and factors associated with cracked nipples in the first month postpartum
}

\author{
Kamila Juliana da Silva Santos ${ }^{1,3^{*}}$, Géssica Silva Santana ${ }^{1}$, Tatiana de Oliveira Vieira', \\ Carlos Antônio de Souza Teles Santos ${ }^{1}$, Elsa Regina Justo Giugliani ${ }^{2}$ and Graciete Oliveira Vieira ${ }^{1}$
}

\begin{abstract}
Background: To assess the prevalence and factors associated with the occurrence of cracked nipples in the first month postpartum.

Methods: This was a cross-sectional study nested in a cohort of mothers living in Feira de Santana, state of Bahia, northeastern Brazil. Data from 1,243 mother-child dyads assessed both at the maternity ward and 30 days after delivery were analyzed. The association between cracked nipples as reported by mothers and their possible determinants was analyzed using Poisson regression in a model where the variables were hierarchically organized into four levels: distal (individual characteristics), distal intermediate (prenatal characteristics), proximal intermediate (delivery characteristics), and proximal (postnatal characteristics).

Results: The prevalence of cracked nipples was $32 \%$ (95\% confidence interval [95 \% Cl] 29.4-34.7) in the first 30 days postpartum. The following factors showed significant association with the outcome: poor breastfeeding technique (prevalence ratio $[\mathrm{PR}]=3.18,95 \% \mathrm{Cl} 2.72-3.72)$; breast engorgement $(\mathrm{PR}=1.70,95 \% \mathrm{Cl} 1.46-1.99)$; birth in a maternity ward not accredited by the Baby-Friendly Hospital Initiative ( $P R=1.51,95 \% \mathrm{Cl} 1.15-1.99)$; cesarean section ( $P R=1.33$, $95 \% \mathrm{Cl} 1.13-1.57)$; use of a feeding bottle ( $P R=1.29,95 \% \mathrm{Cl} 1.06-1.55)$; and higher maternal education level $(\mathrm{PR}=1.23$, $95 \% \mathrm{Cl} 1.04-1.47)$.

Conclusions: The prevalence of cracked nipples was high in our sample. Most of the factors associated with cracked nipples were related to postnatal characteristics, especially poor breastfeeding technique, which could be improved to help prevent the condition.
\end{abstract}

Keywords: Breastfeeding, Lactation disorders, Nipple injuries

\section{Background}

Nipple trauma presents a high incidence, especially in the first 30 days postpartum $[1,2]$. Because it is a painful condition, it often causes interruption of exclusive breastfeeding and early weaning [3, 4]. In the city of New York, $35 \%$ of the women stopped breastfeeding within a week after birth due to nipple trauma, and $30 \%$ between 1 and 4 weeks postpartum [3]. Similarly, in the municipality of Feira de Santana, northeastern Brazil, a

\footnotetext{
*Correspondence: kjulisantos@yahoo.com.br

'State University of Feira de Santana, Bahia, Brazil

${ }^{3}$ Centro de Pós-Graduação em Saúde Coletiva, Mestrado Acadêmico, Avenida

Transnordestina, s/n, Avenida dos Laboratórios, Módulo 6, Bairro Novo

Horizonte, CEP 44036-900 Feira de Santana, BA, Brazil

Full list of author information is available at the end of the article
}

$25 \%$ higher risk of interruption of exclusive breastfeeding was found in the first month of lactation when cracked nipples were present [4].

Several factors have been identified as determinants of nipple trauma in breastfeeding mothers, e.g., poor breastfeeding technique/position/latch-on $[2,5,6]$, use of a feeding bottle $[1,7]$, breast engorgement $[8,9]$, primiparity $[8,10]$, semi-protruding and/or malformed nipples $[8,9]$, use of breast pumps [11], and depigmented nipples [8], among others. Knowledge of the factors involved in the genesis of this condition in specific populations is extremely important to help establish preventive measures, especially because of the little effectiveness associated with the treatment options available $[12,13]$. 
Therefore, the objective of the present study was to investigate the prevalence and factors associated with cracked nipples in the first 30 days postpartum in a cohort of women living in Feira de Santana, state of Bahia, Brazil. The results of the current study may contribute to the design of measures that could help prevent cracked nipples.

\section{Methods}

\section{Study design}

This was a cross-sectional study nested in a cohort study conducted with a sample of mother-child dyads residing in the municipality of Feira de Santana, a large city located in the state of Bahia, northeastern Brazil, $108 \mathrm{~km}$ distant from Salvador, the state capital [14]. In 2012, Feira de Santana had a population of around 568,000 inhabitants. The city is an important economic hub, especially in the fields of commerce, industry, and cattle breeding.

\section{Sample size and data collection}

Sample size for this study was calculated considering the number of live births estimated for year 2003 in Feira de Santana $(10,177)$, an incidence of cracked nipples of $51 \%$, as previously reported [15], an error of $5 \%$, and a $95 \%$ confidence interval (95 \% CI). Sample size calculation resulted in a minimum of 371 mother-child dyads, but 1,309 dyads were interviewed.

Mother-child dyads were recruited at all maternity hospitals serving the municipality of Feira de Santana, at a total of 10 services (public and private), over a 12-moth period, from April 2004 to March 2005. Two maternity hospitals were drawn each time and visited daily, for 2 consecutive months, except for two hospitals conducting a large number of deliveries, which were selected and visited individually. Inclusion criteria were being a resident of Feira de Santana, absence of intercurrences during pregnancy or in the immediate postpartum period, absence of contraindications to breastfeeding, children without any perinatal complication.

All mothers were approached by previously trained health professionals working at a human milk bank, and all signed an informed consent form before undergoing any study procedures. Mothers were interviewed at the maternity ward, and follow-up interviews were conducted at the mothers' homes at $1,2,3,4,5$, and 6 moths postpartum.

A total of 1,360 mother-child dyads were considered eligible for the study. Of those, 1,344 were included in the cohort (10 mothers refused to participate, 4 were unable to inform an address, and 2 resided in areas considered to be unsafe for the research team). At the first follow-up visit, at 30 days, 35 dyads (2.6 \%) were lost, resulting in a total of 1,309 dyads interviewed. The dataset was then filtered to exclude cases with missing information, resulting in a final sample of 1,243 observations for analysis. The results reported in the present study refer to the data collected at the maternity ward and at the 30-day follow-up interview.

A form was developed based on a questionnaire approved by the Center of Excellence and Motivation for Breastfeeding of the Human Milk Bank at Hospital Geral Clériston Andrade, combined with additional questions used by the Brazilian Ministry of Health in the annual assessment of hospitals accredited by the Baby-Friendly Hospital Initiative.

\section{Variables}

For the scope of the present study, cracked nipples were defined based on the mother's report of the presence of cracks in the nipples over the first month postpartum, i.e., any type of damage (cracks, ulcers) to the nippleareolar region [9], associated or not with pain while breastfeeding. This definition did not include pain while breastfeeding alone, i.e., without the presence of cracks. Breast engorgement was defined based on the mother's report of turgid, tense, painful, swollen breasts [16, 17]. Skin color, breast engorgement, and breastfeeding within the first hour after delivery were self-reported by the mothers. Type of nipple was assessed by the interviewer and classified into protruding (normal) or nonprotruding (flat/inverted/pseudo-inverted).

Breastfeeding technique was assessed in all dyads, regardless of the mother's report of cracked nipples. Breastfeeding technique was classified as proper when the baby's body was facing the mother's body; when the baby's mouth was wide open; when the baby's chin touched the breast; when the baby's lips were turned outward; when the nipple presented an elongated, but still round shape after the feed; and when nipple pain was absent. The breastfeeding technique was considered poor or inadequate when any of these criteria were not met.

Previous experience with breastfeeding was considered to be present when the mother reported having breastfed another child. Hospitals were considered to be BabyFriendly when accredited by the Brazilian Ministry of Health's and United Nations Children's Fund's BabyFriendly Hospital Initiative for following the guidelines established in the ten steps to successful breastfeeding.

All these data were collected both at the maternity ward and at the mothers' homes at 30 days postpartum.

\section{Statistical analysis}

In order to assess factors associated with cracked nipples, a conceptual model was established (Fig. 1) with factors hierarchically organized into four levels, according to their proximity to the dependent variable [18]. 


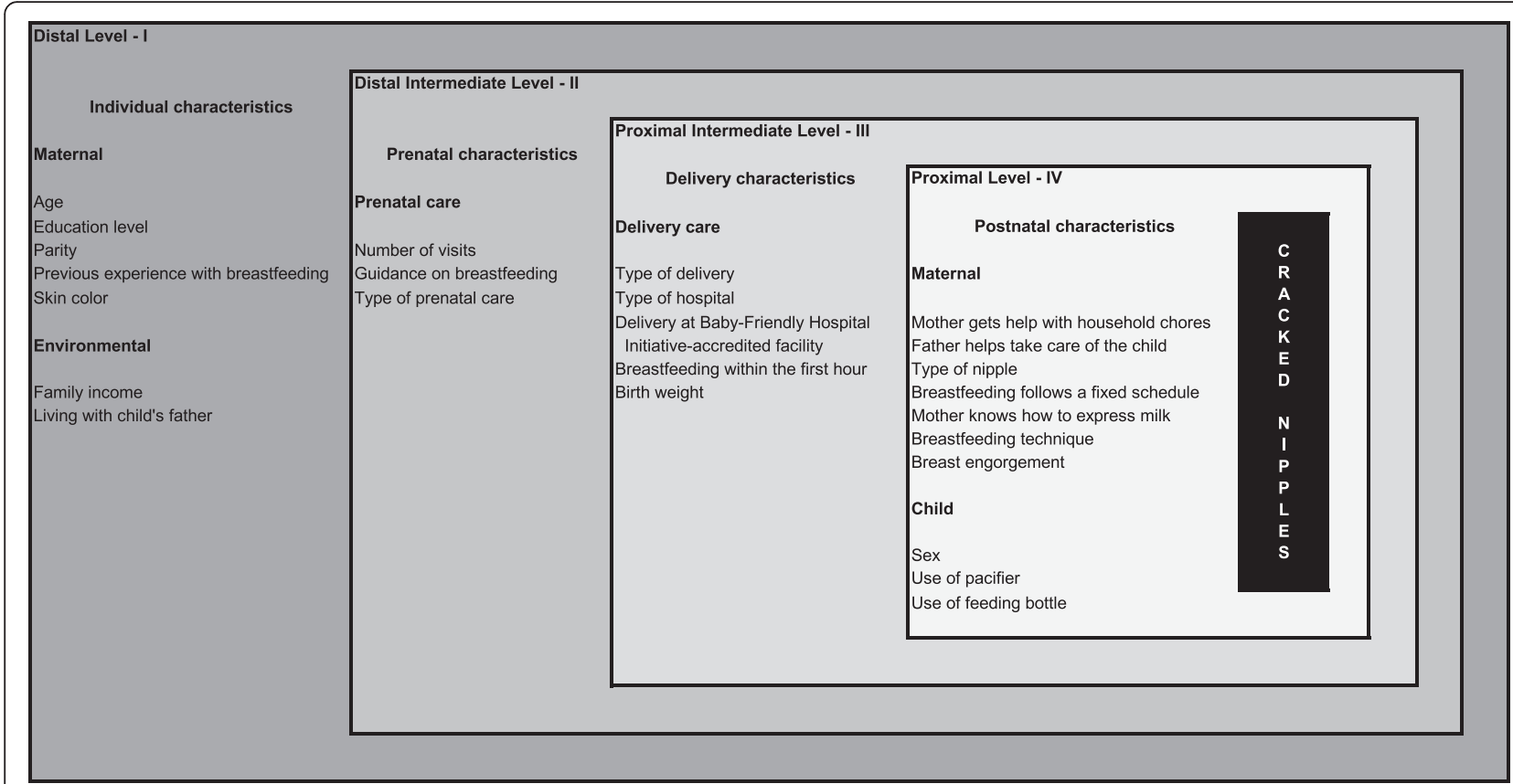

Fig. 1 Hierarchical model of factors potentially associated with cracked nipples

The variables comprising each level were chosen based on established scientific knowledge. In order not to exclude potential confounding factors, any variable reaching a level of significance $\leq 0.20$ in any stage of the analysis was maintained in the model, even if losing statistical significance in subsequent stages. In the final model, only variables reaching a statistical significance of $\mathrm{p} \leq 0.05$ were considered to be associated with the outcome. Poisson regression analysis with robust variance estimation was used to estimate prevalence ratios (PR) and their respective $95 \% \mathrm{CI}$.

In the first stage of regression analysis, the effect of variables included in the more distal level of the hierarchical model was analyzed, with no adjustment for variables belonging to the other levels of proximity. This more distal level was related to the life conditions of the sample assessed, i.e., maternal characteristics (age, education level, parity, previous experience with breastfeeding, skin color) and environmental characteristics (family income and living with the child's father). The second stage of analysis included variables from the first stage that reached significance $(\mathrm{p} \leq 0.20)$, plus variables belonging to the distal intermediate level of the hierarchical model, i.e., prenatal characteristics. A similar procedure was adopted in the third (delivery characteristics) and fourth (postnatal characteristics) stages. Therefore, the final model comprised all variables from the four hierarchical levels that showed a significant association $(\mathrm{p} \leq 0.20)$ with the outcome of interest.
All data collected were double-entered into the Statistical Package for the Social Sciences (SPSS) version 10.0. Statistical analyses were performed in the STATA software version 8.0.

\section{Ethical aspects}

The study was approved by the Research Ethics Committee of Universidade Estadual de Feira de Santana (protocol no. 012/2003). All women included in the study provided written informed consent. Mothers presenting any abnormalities on the clinical breast exam were referred for evaluation and follow-up at Clériston Andrade General Hospital.

\section{Results}

\section{Prevalence of cracked nipples in the first month postpartum}

The prevalence of cracked nipples was $32 \%(398 / 1,243$; $95 \%$ CI 29.4-34.7), but all mothers were still breastfeeding at the 30-day follow-up interview, even in the presence of the outcome. Participation rate was $97.4 \%$ $(1,309 / 1,344)$, and another 66 were discarded due to dataset filtering to exclude cases with missing information, resulting in a final sample of 1,243 dyads included in the analysis.

\section{Factors associated with cracked nipples in the first month postpartum}

According to Table 1, at the first stage of the hierarchical model, maternal education and family income 
Table 1 Prevalence of cracked nipples according to different variables in Poisson regression analysis

\begin{tabular}{|c|c|c|c|c|c|c|c|}
\hline \multirow[t]{2}{*}{ Variables } & \multirow[t]{2}{*}{$N(\%)$} & \multirow{2}{*}{$\begin{array}{l}\text { Cracked nipples } \\
\text { n (\%) }\end{array}$} & \multirow{2}{*}{$\begin{array}{l}\text { First-stage } \\
\text { PR (95 \% Cl) }\end{array}$} & \multirow{2}{*}{$\begin{array}{l}\text { Second-stage } \\
\text { PR (95\% Cl) }\end{array}$} & \multirow{2}{*}{$\begin{array}{l}\text { Third-stage } \\
\text { PR }(95 \% \mathrm{Cl})\end{array}$} & \multirow{2}{*}{$\begin{array}{l}\text { Fourth-stage } \\
\text { PR (95\% Cl) }\end{array}$} & \multirow[t]{2}{*}{$p^{a}$} \\
\hline & & & & & & & \\
\hline \multicolumn{8}{|l|}{ Mother's age } \\
\hline $10-19$ years & $235(18.91)$ & $79(19.85)$ & 1.00 & - & - & - & \\
\hline 20-29 years & $666(53.58)$ & $213(53.52)$ & $0.95(0.76-1.18)$ & - & - & - & \\
\hline 30-39 years & $321(25.82)$ & $100(25.13)$ & $0.99(0.76-1.30)$ & - & - & - & \\
\hline 40-49 years & $21(1.69)$ & $6(1.51)$ & $0.97(0.46-2.03)$ & - & - & - & \\
\hline \multicolumn{8}{|l|}{ Education level } \\
\hline$\leq$ primary school & $445(35.80)$ & $117(29.40)$ & 1.00 & 1.00 & 1.00 & 1.00 & \\
\hline$\geq$ secondary school & $798(64.20)$ & $281(70.60)$ & $1.22(1.00-1.49)$ & $1.24(1.02-1.51)$ & $1.20(0.98-1.46)$ & $1.23(1.04-1.47)$ & 0.016 \\
\hline \multicolumn{8}{|l|}{ Parity } \\
\hline Multiparous & $607(48.83)$ & $160(40.20)$ & 1.00 & - & - & - & \\
\hline Primiparous & $636(51.17)$ & $238(59.80)$ & $1.42(0.66-3.03)$ & - & - & - & \\
\hline \multicolumn{8}{|c|}{ Previous experience with breastfeeding } \\
\hline Yes & $589(47.39)$ & 155 (38.94) & 1.00 & - & - & - & \\
\hline No & $654(52.61)$ & $243(61.06)$ & $0.92(0.43-1.98)$ & - & - & - & \\
\hline \multicolumn{8}{|l|}{ Skin color } \\
\hline Black/brown & $1,013(81.50)$ & $322(80.90)$ & 1.00 & - & - & - & \\
\hline White & $230(18.50)$ & $76(19.10)$ & $0.97(0.77-1.22)$ & - & - & - & \\
\hline \multicolumn{8}{|l|}{ Family income } \\
\hline$\geq 1$ minimum salary & $592(47.63)$ & $209(52.51)$ & 1.00 & 1.00 & 1.00 & 1.00 & \\
\hline$<1$ minimum salary & $651(52.37)$ & 189 (47.49) & $0.82(0.68-0.99)$ & $0.95(0.77-1.16)$ & $0.97(0.79-1.19)$ & $0.95(0.78-1.15)$ & 0.631 \\
\hline \multicolumn{8}{|l|}{ Living with child's father } \\
\hline Yes & $1,070(86.08)$ & $337(84.67)$ & 1.00 & - & - & - & \\
\hline No & $173(13.92)$ & $61(15.33)$ & $1.13(0.90-1.41)$ & - & - & - & \\
\hline \multicolumn{8}{|l|}{ Number of prenatal visits } \\
\hline$\geq 6$ visits & $958(77.07)$ & $310(77.89)$ & - & 1.00 & & - & \\
\hline$<6$ visits & $285(22.93)$ & $88(22.11)$ & - & $1.07(0.87-1.32)$ & & - & \\
\hline \multicolumn{8}{|c|}{ Guidance on breastfeeding received during prenatal care } \\
\hline Yes & $332(26.71)$ & $91(22.86)$ & - & 1.00 & - & - & \\
\hline No & $911(73.29)$ & $307(77.14)$ & - & $1.11(0.91-1.36)$ & - & - & \\
\hline \multicolumn{8}{|l|}{ Type of prenatal care } \\
\hline Public/publicly funded & $841(67.66)$ & $243(61.06)$ & - & 1.00 & 1.00 & 1.00 & \\
\hline Private & $402(32.34)$ & 155 (38.94) & - & $1.34(1.07-1.69)$ & $1.15(0.82-1.60)$ & $1.03(0.82-1.30)$ & 0.760 \\
\hline \multicolumn{8}{|l|}{ Type of delivery } \\
\hline Vaginal & $684(55.03)$ & $184(46.23)$ & - & - & 1.00 & 1.00 & \\
\hline Cesarean section & $559(44.97)$ & $214(53.77)$ & - & - & $1.31(1.07-1.61)$ & $1.33(1.13-1.57)$ & 0.001 \\
\hline \multicolumn{8}{|l|}{ Type of hospital } \\
\hline Public/publicly funded & $920(74.01)$ & $271(68.09)$ & - & - & 1.00 & - & - \\
\hline Private & $323(25.99)$ & 127 (31.91) & - & - & $0.92(0.63-1.33)$ & - & - \\
\hline \multicolumn{8}{|c|}{ Delivery at Baby-Friendly Hospital Initiative-accredited facility } \\
\hline Yes & $312(25.10)$ & $66(16.58)$ & - & - & 1.00 & 1.00 & \\
\hline No & $931(74.90)$ & $332(83.42)$ & - & - & $1.48(1.09-2.00)$ & $1.51(1.15-1.99)$ & 0.003 \\
\hline
\end{tabular}


Table 1 Prevalence of cracked nipples according to different variables in Poisson regression analysis (Continued)

\begin{tabular}{|c|c|c|c|c|c|c|c|}
\hline \multicolumn{8}{|c|}{ Breastfeeding within the first hour after delivery } \\
\hline Yes & $584(46.98)$ & $177(44.47)$ & - & - & 1.00 & - & \\
\hline No & $659(53.02)$ & $221(55.53)$ & - & - & $1.06(0.88-1.27)$ & - & \\
\hline \multicolumn{8}{|l|}{ Birth weight } \\
\hline$\geq 2,500 \mathrm{~g}$ & $1,185(95.33)$ & $381(95.73)$ & - & - & 1.00 & - & \\
\hline$<2,500 \mathrm{~g}$ & $58(4.67)$ & $17(4.27)$ & - & - & $0.92(0.61-1.40)$ & - & \\
\hline \multicolumn{8}{|c|}{ Mother gets help with household chores } \\
\hline Yes & $940(75.62)$ & $304(76.38)$ & - & - & - & 1.00 & \\
\hline No & $303(24.38)$ & $94(23.62)$ & - & - & - & $1.11(0.92-1.34)$ & 0.258 \\
\hline \multicolumn{8}{|l|}{ Father helps take care of the child } \\
\hline Yes & $1,047(84.23)$ & $326(81.91)$ & - & - & - & 1.00 & \\
\hline No & $196(15.77)$ & $72(18.09)$ & - & - & - & $1.15(0.94-1.42)$ & 0.168 \\
\hline \multicolumn{8}{|l|}{ Type of nipple } \\
\hline Normal & $1,178(94.77)$ & $371(93.22)$ & - & - & - & 1.00 & \\
\hline Flat/inverted/pseudo-inverted & $65(5.23)$ & $27(6.78)$ & - & - & - & $1.20(0.90-1.61)$ & 0.205 \\
\hline \multicolumn{8}{|c|}{ Fixed schedule to breastfeed at 30 days } \\
\hline No & 1,191 (95.82) & $376(94.47)$ & - & - & - & 1.00 & \\
\hline Yes & $52(4.18)$ & $22(5.53)$ & - & - & - & $1.09(0.77-1.54)$ & 0.619 \\
\hline \multicolumn{8}{|c|}{ Mother knows how to express excess milk at 30 days } \\
\hline Yes & $885(71.20)$ & $288(72.36)$ & - & - & - & 1.00 & \\
\hline No & $358(28.80)$ & $110(27.64)$ & - & - & - & $1.02(0.86-1.21)$ & 0.752 \\
\hline \multicolumn{8}{|l|}{ Breastfeeding technique } \\
\hline Proper & $1,147(92.28)$ & $314(78.89)$ & - & - & - & 1.00 & \\
\hline Poor & $96(7.72)$ & $84(21.11)$ & - & - & - & $3.18(2.72-3.72)$ & 0.000 \\
\hline \multicolumn{8}{|l|}{ Breast engorgement } \\
\hline No & $830(66.77)$ & $201(50.50)$ & - & - & - & 1.00 & \\
\hline Yes & $413(33.23)$ & $197(49.50)$ & - & - & - & $1.70(1.46-1.99)$ & 0.000 \\
\hline \multicolumn{8}{|l|}{ Child's sex } \\
\hline Female & $578(46.50)$ & $194(48.74)$ & - & - & - & 1.00 & \\
\hline Male & $665(53.50)$ & $204(51.26)$ & - & - & - & $0.87(0.75-1.01)$ & 0.088 \\
\hline \multicolumn{8}{|l|}{ Use of a pacifier at 30 days } \\
\hline No & $734(59.05)$ & $219(55.03)$ & - & - & - & 1.00 & \\
\hline Yes & $509(40.95)$ & $179(44.97)$ & - & - & - & $0.98(0.84-1.16)$ & 0.898 \\
\hline \multicolumn{8}{|l|}{ Use of a feeding bottle at 30 days } \\
\hline No & $1,010(80.26)$ & $297(74.62)$ & - & - & - & 1.00 & \\
\hline Yes & $233(18.74)$ & $101(25.38)$ & - & - & - & $1.29(1.06-1.55)$ & 0.008 \\
\hline
\end{tabular}

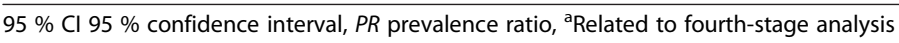

remained in the model. At the second stage, type of prenatal care was associated with the outcome, and at the third stage, type of delivery and delivery at a BabyFriendly Hospital Initiative-accredited facility. Breastfeeding technique, breast engorgement, and use of a feeding bottle at 30 days were the significant variables at the fourth stage of analysis. All these variables were included in the final model. Except for family income and type of prenatal care, all variables selected remained associated with the outcome, even after adjustment for other variables. Therefore, following completion of all analysis stages, the following variables resulted significantly associated with the presence of cracked nipples in the first month postpartum: higher maternal education level, cesarean section, birth at a Baby-Friendly Hospital Initiative non-accredited facility, poor breastfeeding technique, breast engorgement, and use of a feeding bottle. 


\section{Discussion}

\section{Prevalence of cracked nipples in the first month postpartum}

Even though cracked nipples are a long-known problem, and despite major advances in scientific and technological knowledge, the incidence of this condition continues to be extremely high. In the present study, $32 \%$ of the women assessed presented cracked nipples in the first month postpartum. High rates have also been reported by other authors, e.g., $47 \%$ of nipple trauma in the first week in one study conducted in southern Brazil [1], and $44 \%$ at 30 days postpartum in another study [2]. The higher rates found in those studies can probably be explained by the fact that all types of nipple trauma were considered in that sample, vs. only cracked nipples in ours. Also, differences in the incidence of nipple pain/ trauma across studies may be explained, at least in part, by the use of different definitions of nipple trauma and data collection methods. Some studies consider only lesions of continuity of the skin in the nipple-areolar region $[8,19]$, whereas others include any ulcer or skin abnormalities (cracks, excoriations, erosion, ecchymosis, spots, blisters) [2, 5], and yet others consider the mere presence of nipple pain or discomfort while breastfeeding $[13,20]$. In the present study, only the presence of cracked nipples was taken into consideration, associated or not with pain, based on the mothers' report.

\section{Factors associated with cracked nipples in the first month postpartum}

An interesting finding of the present study was the fact that delivery and postnatal characteristics were more strongly associated with the occurrence of cracked nipples than individual and prenatal characteristics.

The variable most strongly associated with cracked nipples in the first month postpartum was poor breastfeeding technique. Women using a poor breastfeeding technique (according to the criteria here adopted) showed a three-fold higher chance of presenting cracked nipples in the first month postpartum. Even though the design of the present study does not allow to state that a causal relationship exists between poor breastfeeding technique and nipple trauma, there is consensus that a proper breastfeeding technique is the most effective preventive strategy and treatment for this outcome [7-9, $12,13,20]$. The few studies that have investigated specific determinants of cracked nipples have also pointed to an association between nipple trauma and poor breastfeeding technique $[5,6]$.

Two other postnatal variables were associated with cracked nipples: breast engorgement and use of a feeding bottle. The association between cracked nipples and breast engorgement has been previously reported $[8,9]$. Breast engorgement changes the anatomy of the nipple region, hindering proper latch-on due to swelling, turgidity, little flexibility, and flat nipples [8]. From a different standpoint, nipple trauma can also cause or worsen breast engorgement, as the pain experienced by the mother may interfere with the frequency and duration of feeds [8].

The use of a feeding bottle, in turn, may be associated with cracked nipples as a consequence of the different sucking techniques required for the bottle and the breast. When fed with a bottle, the child positions her tongue so as to control the flow of milk; use of the same movement on the breast may result in nipple trauma. This association has been demonstrated by Centouri et al. [7] in Italy and by França et al. [1] in Brazil. Notwithstanding, once again, the reverse causality in this relationship should not be disregarded: it is possible that the pain caused by nipple trauma has led the mothers to offer the bottle to their children [1].

Two variables related to delivery care were associated with presence of cracked nipples: cesarean section and delivery at a hospital not accredited by the Baby-Friendly Hospital Initiative. The association between a cesarean section and cracked nipples has been confirmed in some studies [21] and refused in others [10, 19]. It is possible that the pain caused by the surgical incision may affect positioning of the mother-child dyad during breastfeeding. Nevertheless, it has been demonstrated that women who had a cesarean section show better breastfeeding performance when they are assisted in controlling the pain and correcting the child's position while breastfeeding [22]. The use of anesthetics during the surgical procedure may also interfere with the child's ability to suck [10].

Another important finding of our sample that has not been explored in the few previous studies focusing on this topic is the fact that birth at a maternity ward not accredited by the Baby-Friendly Hospital Initiative was a factor associated with cracked nipples. This finding is not surprising, as the routines of accredited hospitals include preventive actions against nipple trauma, e.g., providing guidance on proper breastfeeding techniques, on how to express milk in case of breast engorgement, in addition to the recommendation to avoid the use of a pacifier/bottle [23].

The only individual variable significantly associated with cracked nipples in our sample was higher maternal education level. In Brazil, women with higher education levels have been shown to maintain exclusive breastfeeding for longer [24, 25] - a finding that probably reflects greater awareness of the importance of breastfeeding and a better understanding of the guidance received from health professionals. As a result, we expected that higher maternal education level would protect against cracked nipples, when in fact the opposite was observed. This finding could be related to the fact that the 
occurrence of cracked nipples was self-reported by the mothers, i.e., the information could be biased [26]. Further studies are necessary to confirm and better understand this association, investigating aspects not covered in the present study, e.g., nipple pigmentation and mother's perceptions and appreciation regarding cracked nipples.

\section{Methodological considerations}

One methodological strength of the study is the statistical analysis, in which variables were organized into different levels, allowing to demonstrate that the outcome was more strongly influenced by proximal characteristics. Also, all the professionals involved in data collection were specifically trained for the task and were able to assess and classify the breastfeeding technique according to the criteria established. Conversely, the outcome of interest, cracked nipples, was self-reported by mothers, which may have led to a measurement bias. In our opinion, however, this limitation does not affect the relevance of the study, as we strongly believe that the perception and report of mothers with regard to the presence of cracked nipples is reliable. Moreover, if some women in our sample had cracked nipples but chose not to report the condition, it is likely that the condition had a lower impact on their breastfeeding performance.

\section{Conclusions}

In sum, this study adds to the existing body of knowledge on the factors associated with cracked nipples in the first month postpartum and can help design prevention strategies. According to the present findings, to decrease the prevalence of cracked nipples, it is important to support vaginal delivery and improve the care provided to women who undergo a cesarean section, to incorporate the routines advocated by the Baby-Friendly Hospital Initiative at maternity wards, to guarantee that mothers leave the maternity ward well informed of the proper breastfeeding technique and of how to avoid breast engorgement, and to discourage the use of feeding bottles, regardless of the mother's education level. Finally, it is extremely important that mothers receive appropriate support from trained health professionals with breastfeeding expertise, both in the immediate postpartum period and after discharge.

\section{Abbreviations}

$95 \%$ Cl, $95 \%$ confidence interval; PR, prevalence ratio; SPSS, Statistical Package for the Social Sciences

\section{Acknowledgements}

Not applicable.

Funding

The present study did not receive any financial support.

\section{Availability of data and materials}

The datasets generated and analyzed during the current study are stored in the repository belonging to Núcleo de Pesquisa e Extensão em Saúde (NUPES) of Universidade Estadual de Feira de Santana. The data are not publicly available online, but they can be obtained from the corresponding author upon request.

\section{Authors' contributions}

KJSS conceived the current study hypothesis, designed the cohort, performed the analysis, drafted the paper and supervised the writing of the manuscript. GSS supervised the writing of the manuscript. TOV carried out the interpretation of data and provided substantial contributions to manuscript writing. CASTS performed the analysis and provided substantial contributions to data interpretation. ERJG provided substantial contributions to data interpretation and manuscript writing. GOV conceived the current study hypothesis, conducted the cohort, and drafted the paper. All authors helped to interpret the findings, read and approved the final manuscript.

\section{Authors' information}

Not applicable.

Competing interests

The authors declare that they have no competing interests.

\section{Consent for publication}

All participants provided written consent to publish the data collected.

\section{Ethics approval and consent to participate}

The study was approved by the Research Ethics Committee of Universidade Estadual de Feira de Santana (protocol no. 012/2003). All women included in the study provided written informed consent to participate in the study.

\section{Author details}

${ }^{1}$ State University of Feira de Santana, Bahia, Brazil. ${ }^{2}$ Federal University of Rio Grande do Sul, Rio Grande do Sul, Brazil. ${ }^{3}$ Centro de Pós-Graduação em Saúde Coletiva, Mestrado Acadêmico, Avenida Transnordestina, s/n, Avenida dos Laboratórios, Módulo 6, Bairro Novo Horizonte, CEP 44036-900 Feira de Santana, BA, Brazil.

Received: 13 January 2016 Accepted: 29 July 2016

Published online: 05 August 2016

\section{References}

1. França MCT, Giugliani ERJ, Oliveira LD, Whigert EML, Santo LCE, Köhler CV, et al. Bottle feeding during the first month of life: determinants and effect on breastfeeding technique. Rev Saude Publica. 2008:42:607-14.

2. Weigert EM, Giugliani ER, França MC, de Oliveira LD, Bonilha A, Santo LCE, et al. The influence of breastfeeding technique on the frequencies of exclusive breastfeeding and nipple trauma in the first month of lactation. J Pediatr (Rio J). 2005:81:310-6.

3. Ahluwalia IB, Morrow B, Hsia J. Why do women stop breastfeeding? Findings from the pregnancy risk. Assessment and monitoring system. Pediatrics. 2006;116:1408-12.

4. Vieira GO, Martins CC, Vieira TO, de Oliveira NF, Silva LR. Factors predicting early discontinuation of exclusive breastfeeding in the first month of life. J Pediatr (Rio J). 2010;86:441-4.

5. Coca KP, Gamba MA, Silva RS, Abrão ACFV. A posição de amamentar determina o aparecimento do trauma mamilar? Rev Esc Enferm USP. 2009:43:446-52.

6. Goyal R, Banginwar A, Ziyo F, Toweir A. Breastfeeding practices: positioning, attachment (latch-on) and effective suckling: a hospital-based study in Libya. J Family Community Med. 2011;18:74-9.

7. Centuori S, Burmaz T, Ronfani L, Fragiacomo M, Quintero S, Pavan C, et al. Nipple care, sore nipples, and breastfeeding: a randomized trial. J Hum Lact. 1999;15:125-30.

8. Coca KP, Gamba MA, Silva RS, Abrão ACFV. Factors associated with nipple trauma in the maternity unit. J Pediatr (Rio J). 2009;85:341-5.

9. Vinha VH, Pelá NT, Shimo AK, Scochi CG. Trauma mamilar: proposta de tratamento. Femina. 1987;15:370-8. 
10. Shimoda GT, Silva IA, Santos JLF. Características, frequência e fatores presentes na ocorrência de lesão de mamilos em nutrizes. Rev Bras Enferm. 2005;58:529-34.

11. Qi Y, Zhang Y, Fein S, Wang C, Loyo-Berríos N. Maternal and breast pump factors associated with breast pump problems and injuries. J Hum Lact. 2014:30:62-72

12. Morland-Schultz K, Pamela D, Hill PD. Prevention of and therapies for nipple pain: a systematic review. J Obstet Gynecol Neonatal Nurs. 2005;34:428-37.

13. Cadwell K, Turner-Maffei C, Blair A, Brimdyr K, Mclnerney ZM. Pain reduction and treatment of sore nipples in nursing mothers. J Perinat Educ. 2004;13:29-35.

14. Vieira TO, Vieira GO, de Oliveira NF, Mendes CM, Giugliani ER, Silva LR. Duration of exclusive breastfeeding in a Brazilian population: new determinants in a cohort study. BMC Pregnancy Childbirth. 2014;14:175.

15. Livingstone VH, Willis CE, Berkowitz J. Staphylococcus aureus and sore nipples. Can Fam Physician. 1996;42:89-99.

16. Giugliani ERJ. Common problems during lactation and their management. J Pediatr (Rio J). 2004;80 Suppl 5:147-54.

17. Newton M, Newton NR. Postpartum engorgement of the breast. Am J Obstet Gynecol. 1951;61:664-7.

18. Victora CG, Huttly SR, Fuchs SC, Olinto MT. The role of conceptual frameworks in epidemiological analysis: a hierarchical approach. Int J Epidemiol. 1997;26:224-7.

19. Coca KP, Abrão ACFV. Avaliação do efeito da lanolina na cicatrização dos traumas mamilares. Acta Paul Enferm. 2008;21:11-6.

20. Tait P. Nipple pain in breastfeeding women: causes, treatment, and prevention strategies. J Midwifery Womens Health. 2000;45:212-5.

21. Peres JAT. Uso da lisozima na fissura da mama puerperal. J Bras Ginecol. 1980;90:317-9

22. Franz KB, Kalmen BA. Breastfeeding works for cesareans too. RN. 1979;42:39-47.

23. Brasil, Ministério da Saúde, Secretaria de Atenção à Saúde, Departamento de Ações Programáticas Estratégicas. Iniciativa Hospital Amigo da Criança. Brasília: Ministério da Saúde; 2011.

24. Damião JJ. Influência da escolaridade e do trabalho maternos no aleitamento materno exclusivo. Rev Bras Epidemiol. 2008;11:442-52.

25. Escobar AMU, Ogawa AR, Hiratsuka M, Kawashita MY, Teruya PY, Grisi S, et al. Aleitamento materno e condições socioeconômico-culturais: fatores que levam ao desmame precoce. Rev Bras Saude Mater Infant. 2002;2:253-61.

26. Chapman DJ, Pérez-Escamilla R. U.S. National Breastfeeding Monitoring and Surveillance: current status and recommendations. J Hum Lact. 2009:25:139-50.

\section{Submit your next manuscript to BioMed Central and we will help you at every step:}

- We accept pre-submission inquiries

- Our selector tool helps you to find the most relevant journal

- We provide round the clock customer support

- Convenient online submission

- Thorough peer review

- Inclusion in PubMed and all major indexing services

- Maximum visibility for your research

Submit your manuscript at www.biomedcentral.com/submit

) Biomed Central 